\title{
Exploring the Role of Industrial Districts to Design and Implement Age-aware E- services and Policies
}

\author{
Paolo Depaoli $^{1}$ Maddalena Sorrentino $^{2}$ Marco De Marco ${ }^{3}$ \\ ${ }^{1}$ CeRSI-LUISS University, Rome, Italy.Email: paolo.depaoli@uniurb.it \\ ${ }^{2}$ Università degli Studi, Milan, Italy.Email: maddalena.sorrentino@unimi.it \\ ${ }^{3}$ Università Cattolica, Milan, Italy.Email: marco.demarco@unicatt.it
}

\begin{abstract}
We examine the basic issues concerning the interplay of ICT-IS with an ageing society and the 'e-Inclusion' strategy developed by the European Union (EU). We claim that, because of their innovative traits, Italian industrial districts represent appropriate environments for the implementation of public policies in support of an ageing information society. In fast growing countries, such as China, this approach could spur the development and the competitiveness of both e-services and small and medium size firms (SMEs). Present agreements between China and the EU can fuel appropriate research and ventures in relevant fields.
\end{abstract}

Keywords: SMEs, ageing society, ICT services, e-Inclusion

\section{Introduction}

There is agreement in the literature concerning the increasing weight of the elderly (people aged over 65) on the total population in the world[1]. There is also convergence on the concerns raised by the phenomenon which relate, on the one hand, to the willingness to take into account the specific needs of a growing part of the population (which detains an increasing voting weight and disposes of higher economic means than younger co- horts) and, on the other hand, the affordability for national budgets to satisfy such needs on the basis of current health and care schemes. A number of services have been developed along the years, in part provided by public authorities, in part offered by private companies and partially or totally covered by insurance contracts; furthermore, the issues raised by an ageing population are not only economic but relate to the social standing of the elderly and their right to be both as independent as possible and integrated in their living and working communities [2].

Information and communication technologies (ICTs) are being explored to evaluate their potential in finding solutions to such concerns: distance monitoring of conditions of patients in appropriate 'smart houses' can reduce hospitalization time, thus decreasing costs, especially when chronic diseases are encountered [3]. The access to the Internet can facilitate the acquisition of information on leisure services or on-line purchase of goods and services for the elderly with weakened mobility, thus increasing the instances of independent action [4]. Appropriate information systems (IS) applications can facilitate the use and circulation of the experience of older knowledge workers [5] if interfaces are properly designed to balance the diminished visual and hearing capabilities that start affecting people in their fifties [6]. 
The market of such ICT enhanced services is still in its infancy because both demand and supply have to overcome barriers that hinder their development [7]. Awareness building is therefore needed for both consumers and producers and appropriate policies can play a positive role in sustaining growth in this collection of industries by both reducing barriers and offering incentives for searching and deploying new services and technologies connected via the Internet. The role of public authorities is thus apparent: to ensure access (by all categories of users) to age-aware ICT enabled services, to define standards of quality for their supply, to support market players in research, development and implementation activities, and, of course, to define the scope, the extent and character of its own presence.

There two current gaps in understanding: (i) governments in ageing societies need to better understand how to expand and overhaul their service portfolios; (ii) product developers and service providers need to better understand how to develop an offering which serves the fairly different needs and wants of ageing societies.

The paper pursues two aims: (i) exploring how information and communication technologies and information systems (ICT-IS), are thought to affect the elderly, since ageing is considered to be a phenomenon of increasing importance; (ii) investigating what criteria can be adopted in implementing a policy meant to support the diffusion of an age-aware ICT-IS.

This paper claims that industrial districts promote both innovation and social inclusion, therefore it addresses the following research question: What are the advantages of leveraging 'industrial districts' to spur innovation and implement public policies in ICT age-aware services?

Being 'conceptual' this paper qualitatively explores aspects of interconnected phenomena and highlights significant relations among them. Methodologically it uses an exemplary case: the European policy concerning ICT and ageing and the Italian industrial districts (as a possible favourable implementation milieu).

The paper is structured as follows. Section two explains the theoretical foundations of the study. Key issues related to an ageing population are considered in section three. The advantages of referring to local industrial communities to implement policies and spur innovation are presented in sections four and five. Conclusions and implications are in section six.

\section{Theoretical underpinnings}

Many theories have been developed to explain the interplay of technology, users (the elderly and their world), private firms (technology producers and service providers) and public authorities (policy designers and implementers). We chose an overarching theoretical framework that we believe highly suited to the reflection we plan to make, namely the widely known Institutional Theory. Viewed from a neo-institutional perspective, an industrial district represents an integrated 'relational system' (i.e. a system built up upon connections among individual and collective actors, [8]). We assume that districts, being institutions made up of rules, norms and cultural beliefs and material resources [8:39], provide meaning and influence the way stakeholders define their interests and preferences. From the institutional perspective, we also draw on arguments from Whitley's research on business systems and innovation [9] to evaluate districts as social productive contexts capable of developing new ageaware ICT platforms and related services.

To outline the socio-economic profile of districts we utilize both the pioneer work of Beccattini [10] and successive research [11] [12]. Nonaka's contribution [13] is used to interpret the role of tacit 
knowledge in these areas. Further, part of our discussion builds upon Putnam's work [14] on the social capital of the Italian regions to show the positive implications that the endowment of this powerful asset has in spurring a market of ICT enhanced services for ageing.

\section{Key issues concerning ageing and policy making}

Data [15] show that the world population over 65 was $6.5 \%$ in 1970 , and not much larger in $2008(7.6 \%)$, even though it is forecasted to be $16.7 \%$ in 2050 . There are a number of (policy relevant) social and economic issues connected to this phenomenon which the evolution of information technology intersects.

\subsection{Ageing and socio-economic issues}

As mentioned in the introduction, one key aspect of an ageing society is the search for a balance between increasing national budget constraints and the intention to satisfy the needs of the elderly. A possible answer lies in building an appropriate mix of public and private services and the question thus centers on the amount of 'commoditization' deemed to be acceptable in a given social context [16]. In fact, the issues raised by an ageing population are not only of an economic nature (what amount of private and public resources should be transferred), but also relate to the social standing of the elderly and their right to be both as independent as possible and integrated in their living and working communities [17]. As highlighted by Castells [18], the notion of lifecycle is breaking down since, for example, the 'third age' no longer coincides with the exit from the labor market and many people are living one-third of their life after this event, making possible a number of once marginal or even unthinkable roles (such as late parenthood).

\subsection{Technology, e-services and rele- vant issues concerning ageing}

Mobility is one of the areas where the development of ICT solutions is necessary to increase an older person independence. 'Assisted living environments', a form of 'smart houses', constitute a research area [19] where sensors, home networks and communications are employed to monitor the occupants of a given environment to ensure their safety. The increase in safety helps the elderly prolong their living in familiar surroundings and augments the possibility of being taken care of at home, thus potentially reducing the demand of nursing home services.

A decisive aspect of ICTs and ageing is however connected with learning how to cope with different devices and with the Internet as a means to access public services, available through e-Government applications, or to private ones for entertainment, or, simply, to interact with friends and relatives. The underlying question is linked to technology design for its usability [20]. Furthermore, the trade-off between privacy and home care systems has to be considered not only as a regulatory conundrum (safety vs. privacy, [21]) but also as the extent to which these systems are going to be accepted. In fact, elderly people seem to be particularly sensitive about the intruding character of technology [22].

The management of these issues and the growth of an appropriate market requires harmonized policies to promote expertise and innovation in these services supported by ICTs.

\subsection{The European policy concerning e-inclusion and ageing}

In 2006 the European Union (EU) policy for e-inclusion was stated in the "Riga Ministerial Declaration on an Inclusive Information Society" [23]. In the declara- 
tion, the term e-inclusion stands for both inclusive ICTs and ICTs considered as enablers in achieving inclusion objectives.

One year after the Riga Declaration, the "Action Plan on Information and Communication Technologies and Ageing - Ageing well in the information society" [24], was launched. The Action Plan aims at building critical mass and overcoming regulatory barriers to ground a single European market. In fact, products and services are currently based on national or local needs because of different reimbursement, service delivery and certification schemes [25:36]. These factors limit interoperability and restrict the potential of e-health and of e-government services. The resulting fragmentation of the industry (estimates indicate 20.000 assistive technology products in Europe [25:38]) causes lack of economies of scale and high costs for users and insurers. Regulatory uncertainties lower the propensity to commit resources in an industry where returns are not immediate and investments high.

SMEs interested in enlarging their current national niche markets may propose projects to be funded in the main areas addressed by the European Action Plan: 'Ageing well at work', 'Ageing well in the community', and 'Ageing well at home' [24:4].

\section{The industrial district milieu: a "natural laboratory"}

Small and medium size enterprises (SME) are the most diffused type of economic organization in the world. Whitley [9] has highlighted the interconnections among institutional contexts, types of firms and innovation strategies. Typical innovation strategies implemented by SMEs can be defined as 'responsive' since "they compete by making rapid and continuing changes in product qualities to suit customer needs" [9:875]. These responsive strategies are typical of industrial districts which have been extensively studied in the OECD countries [26, 27]. The following definition summarizes the characteristics of districts (or 'clusters'): "geographically close groups of interconnected companies and associated institutions in a particular field, linked by common technologies and skills. They normally exist within a geographic area where ease of communication, logistics and personal interaction is possible. Clusters are normally concentrated in regions and sometimes in a single town" [28] .

Italy is the Western country where districts have the most considerable weight [27]: $40 \%$ of the country's manufacturing companies, i.e. 200,000 plants, are located in these areas and account for $40 \%$ of Italian employment in manufacturing; further, 5 million families - one-fifth of the total - and one-fourth of the 8,000 municipalities are situated in these territories [29]. Most of the above-cited literature on 'industrial districts' and 'clusters' (and specifically [30]) actually consider the Italian case to be exemplary of the traits of such environment.

\section{The opportunities stemming from the entrepreneurial and social pro- file of districts}

The contours of districts - not limited to those in Italy - have been drawn [31]: i) physical proximity is a key element because it facilitates personal contacts among firms; ii) relational resources are more critical than infrastructural externalities; and iii) a number of actors besides firms (trade associations, local authorities, universities and other local institutions) are a constituent part of the relational resources. One of the outcomes of these ongoing relations (probably linked to proximity) is 'collective learning', that is, "a social process of cumulative knowledge based on a set of shared rules and 
procedures which enable individuals to coordinate their actions in the search for problem solutions" [32:162]. So a district develops a local knowledge that is basically 'tacit' [30] external to each individual firm. From Nonaka's work [13] we know that an appropriate 'context of interaction', and the presence of an 'intentional actor' (a leader) allows for the creation of new knowledge. At district level this leading role can possibly be found in key firms that have been emerging in several districts as lead companies [11].

One support to our claim that districts can be an ideal laboratory for developing new products and services (aligned with the needs of the elderly) is exactly their capability to evolve (to learn). No matter how different, and at times contrasting, the interpretations proposed by scholars and researchers, in districts there exist fine grained tissues of small firms capable of responding to changing requests which are interrelated with larger key ('focal') firms capable of evaluating emerging opportunities concerning markets and technologies in a global perspective [11]. So that information and formalized knowledge coming from distant actors can vivify local rich tacit knowledge (and vice versa) [12]. Information technology innovation, applied to an important social issue such as ageing, is itself a further stimulus to enhance local and global forms of cooperation.

The endowment of districts with social capital indicates that common codes, norms and values are shared by people living in the district communities [8] so that user groups can more easily converge on usability/non usability evaluations of new products and services on the parts of providers. This remark is crucial when considering that any strategy concerning the delivery of public services, besides being attentive to technological, organizational and inclusion issues, must leverage other resources to integrate digital and inpresence public services [33].

In the light of the characteristics of industrial districts (and emblematically of the Italian ones) it can be argued that the innovative manufacturing enterprises, typical of these areas, are able to develop the 'supply' side of this market. In fact, their modus operandi learns from experience and from the interactions with clients (whether end users or other firms within the supply chain). The small size helps the informal interaction of the team headed by the entrepreneur and boosts rapid decision making, the improvement of current products and services, the design of new ones, the experimenting of new materials, and the introduction of process change and state of the art procedures. This capability to understand the emerging needs of demand and to undertake innovative actions is necessary to implement policy goals. Capabilities in personalization enable SMEs to adhere to the diverse and evolving needs of the elderly, sensitive to local culture and specific physical surroundings. The fact that, to help European market growth, the Action Plan on ICT and Ageing supports both research and pilot projects (cofunded with private resources) builds on the autonomous propensity to innovate on the part of district SME and is a further stimulus for them to co-operate with larger mainstream ICT companies thus entering an increasingly attractive European market. In fact, district companies are already used to serve international markets so that they do not have to overcome competence and culture barriers for international co-operation (a distinctive feature with respect to average non-district SME).

The traits of the Italian districts also help the 'demand' side of the market which the European policy intends to promote and to expand. The closely knit social tissue of districts, the 'open' mind 
set of a population that works in innovative and fast changing firms (a workforce used to inter-firm mobility and to a constant upgrading of knowhow), the endowment of social capital, which rests upon trust, constitute a favorable environment for the demand of new products and services for the elderly. The problems of information asymmetries (users in weaker positions in understanding complex products and services), that justifiably worry policy makers, are more easily tackled and overcome in district milieus.

\section{Concluding remarks and implica- tions}

The answer to the research question addressed by this paper is that the traits of industrial districts (specifically the Italian ones) make them an appropriate and receptive environment to implement policies (in this case the EU e-inclusion policy for the ageing society) based on a multichannel delivery of services.

Therefore, the contribution that our paper proposes to regional and local policy makers is to consider districts as a 'laboratory' to calibrate policy measures and assess the reaction of both demand and supply (by means of pilot studies, of product and service development and deployment in close contact with private firm and not-for-profit organizations). An evaluation which is particularly helpful in the field of ageing-aware technologies where 'technical' aspects have to properly interact with 'socio-economic' networks for these technologies to be accepted. The existence of local communities that share common productive and social interests, is a positive sign for pursuing collaborative arrangements (among local authorities and in partnership with local enterprises and organizations) on ageing issues and specifically on eservices based solutions (both private and e-government ones).
The stakeholders that are involved in the development of such services, besides public authorities, are several and their actions will condition the actual growth of the relevant market. For entrepreneurs districts can be an interesting market test for their innovating endeavors and are large enough to orientate their development activities. Professionals involved in home care work, are able to develop their interaction with Ambient Assisted Living solutions in situations where the existing social networks (in addition to the elderly themselves) can give them an appropriate feedback. End users are protected in their choices and usage by a large socioeconomic network that provides them with the necessary information and assistance. Finally, larger ICT companies can count on a rich tissue of SME that detain precious information on user needs and preferences and can co-operate with them in a prompt, competent and export oriented manner.

Some of the characteristics of Chinese SMEs recall the traits of districts enterprises, for example: flexible and informal human resources management [34], the positive impact on innovation performance of inter-firm cooperation [35], the leverage of social networks (guanxi) in successful internationalization [36]. Of course, further research is needed to provide better understanding of similarities and differences in SMEs and in ageaware e-services and policies between the European Union and China. Possible joint research ventures can be explored within "The agreement for scientific and technological cooperation between the European Community and the Government of the People's Republic of China" [37].

\section{References}

[1] Demeny, P., McNicoll, G. (eds.), "The Political Economy of Global Population Change 1950-2050”. Sup- 
plement to Vol. 32 of Population and Development Review, Population Council, New York, 2006

[2] Edwards, P., "Active Ageing: a Policy Framework", World Health Organization Press, Geneva, 2002

[3] Vergados, D., Alevizos A., Caragiozidis, M., Mariolis, A., "Intelligent Services for Assisting Independent Living of Elderly People at Home", Proceedings, Conference on Pervasive Technologies Related to Assistive Environments, ACM, New York, 2008

[4] Czaja, S. J., Lee, C.C., "The impact of the Internet on Older Adults". In Charness, N., Schaie, K.W. (eds.) Impact of Technology on Successful Ageing, Springer, New York, 2003

[5] Börsch-Supan, A., "First Results from the Survey of Health, Ageing and Retirement in Europe (2004-2007)", MEA, Mannheim, 2008

[6] Hanson, V.L., "Age and Web Access: The Next Generation", Proceedings, 18th International World Wide Web Conference, ACM, New York, 2009

[7] Stack, J., Zarate, L., Pastor, C., Mathiassen, N.E., Barberà R., Knops, H., Kornsten, H., "Analysing and federating the European assistive technology ICT industry", European Commission, Bruxelles, 2009

[8] Scott, R.W. (2003) "Institutional Carriers: Reviewing modes of transporting ideas over time and space and considering their consequences", Industrial and Corporate Change,. 12, 4, 879-894

[9] Whitley, R., "The institutional Structuring of Innovation Strategies: Business Systems, Firm Types and Patterns of Technical Change in Different Market Economies", Organization Studies, 21, 5, 2000, pp. 855-886

[10] Becattini, G., 'The Marshallian industrial district as a socio-economic notion' in Industrial districts and in- ter-firm co-operation in Italy. Fyke, F., Becattini, G., and Sengenberger, W. (eds.), ILO, Geneva, 1990, pp. 3751

[11] Lazerson, M., and Lorenzoni G., "Resisting Organizational Inertia: The Evolution of Industrial Districts", Journal of Management and Governance, Vol. 3, 1999, pp. 361-377

[12] Camuffo, A, "Transforming Industrial Districts: Large Firms and Small Business Networks in the Italian Eyewear Industry", Industry and Innovation, Vol. 10, N. 4, 2003, pp. 377-401

[13] Nonaka, I., "A dynamic theory of organizational knowledge creation". Organization Science, 5(1), 1994, pp. 14-37

[14] Putnam, R.D., "Making Democracy Work. Tradition in Modern Italy", PUP, Princenton. NJ, 1993

[15] Bureau of the Census, http://www.census.gov/ipc/www/idb/t ables.html\#region

[16] Knights, D., Morgan G., “Organization Theory and Consumption in a Post-Modern Era", Organization Studies, 14/2, 1993, pp. 211-234

[17] Edwards, P. "Active Ageing: a Policy Framework", World Health Organization Press, Geneva, 2002

[18] Castells, M. "The rise of the network society", Blackwell, London, 2000

[19] Wang, F., Turner. J.K., "Towards Personalised Home Care Systems". Proceedings, Conference on Pervasive Technologies Related to Assistive Environments, ACM, New York, 2008

[20] Bélanger, F., Carter L., "The utilization of e-government services: citizen trust, innovation and acceptance factors" Information Systems Journal, Routledge, London, 2005, 15, pp. 525 
[21] Moncrieff, S., Venkatesh, S., West, G., "Privacy and the Access of Information in a Smart House Environment", Proceedings, Conference "Multimedia", ACM, New York, 2007

[22] McCreadie, C., Tinker, A. "The acceptability of assistive technology to older people", Ageing and Society, 25, 2005, 91-110

[23] EU, "Riga Ministerial Declaration on an Inclusive Information Society", June 11, 2006

[24] Communication from the Commission "Ageing well in the Information Society An i2010 Initiative - Action Plan on Information and Communication Technologies and Ageing" \{SEC(2007)811\}

[25] European Commission staff working document. "Action Plan on Information and Communication Technologies and Ageing - Impact Assessment", Bruxelles, 2007

[26] European Commission, "Regional clusters in Europe", Observatory of European SMEs, No. 3, 2002

[27] OECD, "Competitive Regional Clusters", Paris 2007

[28] Porter, M., "The Economic Performance of Regions", Regional Studies, Vol. 37, 2003, pp. 549-578

[29] ISTAT, "Distretti industriali e sistemi locali del lavoro 2001", ISTAT, Rome, 2005

[30] Molina-Morales, F.X., LópezNavarro F.X., Guia-Julve, J. "The role of local institutions as intermediary agents in the industrial districts", European Urban and Regional Studies, 9 (4), 2002, pp. 315-329
[31] Molina-Morales, F.X., MartinezFernandez, M.T., "Industrial districts: something more than a neighbourhood", Entrepreneurship \& Regional Development, 18, November 2006, pp. 503-524

[32] Capello, R., "Spatial Transfer of Knowledge In High Technology Milieux: Learning Versus Collective Learning Processes", Regional Studies, Vol. 33.4, 1999, pp. 353-365

[33] Jan Gulliksen, J, von Axelson, H., Persson, H., Goransson, B., "Accessibility and Public Policy in Sweden", Interactions, ACM, Vol. XVII.3, May-June 2010, pp. 26-29

[34] Cunningham, L. X., Rowley, C., "Small and medium-sized enterprises in China: a literature review, human resource management and suggestions for further research", Asia Pacific Business Review, 16/ 3, 2010, pp. 319-337

[35] Zeng, S.X., Xie, X.M., and Tam, C.M., "Relationship between cooperation networks and innovation performance of SMEs", Technovation, 30/3, 2010, pp. 181-194

[36] Xie, Y. H., Amine, L. S., "Social networks and the internationalization of Chinese entrepreneurs", Global Business \& Organizational Excellence, 29/1, 2009, pp. 61-78

[37] EU, ““"The agreement for scientific and technological cooperation between the European Community and the Government of the People's Republic of China", Official Journal of the European Communities, Bruxelles, 11.1.2000 